\title{
An optimization of hematopoietic stem and progenitor cell isolation for scientific and clinical purposes by the application of a new parameter determining the hematopoietic graft efficacy
}

\author{
B. Baumert, K. Grymuła, D. Pietruszka, M. Kotowski, M. Mielczarek, V. Dziedziejko, \\ M. Hałasa, B. Czerny, M. Walczak, B. Machaliński
}

Department of General Pathology, Pomeranian Medical University, Szczecin, Poland

\begin{abstract}
The transplantation of hematopoietic stem and progenitor cells (HSPC) is an established lifesaving therapy. Bone marrow (BM), harvested from heparinized cadaveric organ donors, peripheral blood (PB) and cord blood (CB), are important sources of hematopoietic stem cells. HSPCs, which are used for transplantation purposes, are routinely evaluated in terms of number of mononuclear cells (MNCs), $\mathrm{CD} 34^{+} \mathrm{MNCs}$ count and viability. The efficacy of grafting is determined additionally in clonogenic tests in vitro. These tests deliver important information about the number of HSPCs and their proliferative potential. Unfortunately, they do not give a possibility to evaluate the functional HSPC chemotactic reactivity in the SDF-1 gradient, which is probably the key phenomenon for HSPC homing after transplantation procedure. Thus, the aim of our study was to optimize HSPC isolation according to their chemotactic reactivity in SDF-1 gradient. Using multiparameter cell sorter (FACS Aria, BD) we examined the HSPCs attracted by SDF-1 on a single cell level. The population of cells which participated in the chemotactic process was highly enriched in $\mathrm{CXCR} 4^{+}$lin-AC1 $33^{+} \mathrm{CD} 45^{+}$cells (referred as hematopoietic stem cells) and to our surprise in $\mathrm{CXCR} 4^{+}{ }^{+}{ }^{-}{ }^{-} \mathrm{AC} 133^{+} \mathrm{CD} 45^{-}$cells (referred as pluripotent stem cells) in quantitative amounts. Since reactivity of HSPCs may depend on various factors involved in the protocol of their isolation and short-term storage, we tested the most commonly used anticoagulants (ACD, CPDA-1, EDTA and Heparin) and culture media (DME, IMDM, RPMI). HSPCs, harvested from CB, PB and BM, were subsequently investigated for clonogenic growth of CFU-GM in methylcellulose cultures and for the level of apoptosis by employing annexin V staining. Evaluating clonogenic potential, ability of chemotactic reactivity in SDF-1 gradient and intensification of apoptosis of HSPC as the most safe anticoagulant and medium were selected. This study has proved that chemotactic reactivity of HSPCs is a new but very important parameter which should be included in the procedure of their isolation.
\end{abstract}

Key words: SDF-1 gradient - Chemotaxis - Stem/progenitor cells - Pluripotent stem cells

\section{Introduction}

The transplantation of hematopoietic stem and progenitor cells (HSPCs) is an established method for treating various hematopoietic and immunological disorders. HSPCs harvested from bone marrow (BM), mobilized peripheral blood (mPB) and cord blood (CB) for transplantation purposes are routinely evaluated in terms of number of mononuclear cells (MNCs), MNCs CD34 count and their viability. The efficacy of grafting is sometimes determined additionally in clonogenic in

Correspondence: B. Machalinski, Dept. General Pathology, Pomeranian Medical University, Powstancow Wlkp. 72, 70-111 Szczecin, Poland; e-mail: machalin@sci.pam.szczecin.pl vitro tests. All these tests deliver important information about the number of cells and their proliferative potential. However, they do not give a possibility to evaluate the functional HSPC chemotactic reactivity in the SDF-1 gradient, which is probably the key phenomenon for homing after transplantation procedure.

Chemokine SDF-1 (stromal-derived factor-1) binds to CXCR4, and CXCR4 is the only crucial receptor for SDF-1, which suggests, that SDF-1/CXCR4 axis plays a significant biological role [1-3]. SDF-1 is a powerful chemoattractant for HSPCs, pre-B and T lymphocytes, produced by stromal cells, including those from the bone marrow [4-5]. During late embryonic development, both human and murine stem cells migrate from the fetal liver via the blood circulation, home to the 
bone marrow and repopulate the tissue with high levels of immature and maturing cells. Murine embryos, which lack the chemokine SDF-1 or its receptor CXCR4, have lethal defects including impaired seeding of the fetal bone marrow [6]. In SDF-1 or CXCR4 knockout mice, hematopoietic precursors do not shift to the bone marrow during fetal development, suggesting that SDF-1 plays an important role in the migration of HSPCs to the bone marrow [7-9]. SDF-1 mediated migration of human HSPCs in vitro correlates with their in vivo repopulation potential in transplant patients [10]. Presumably, a few stages of cell isolation can influence the reactivity of HSPC in SDF-1 gradient.

To deal with this problem we evaluated the chemotactic reactivity of human $\mathrm{CB}, \mathrm{PB}$ and $\mathrm{BM}$ cells in SDF-1 gradient among the population of hematopoietic stem cells (HSCs) and non-hematopoietic pluripotent stem cells (PSCs) using a multiparameter sorting on a single cell level. Moreover, we optimized some selected stages of HSPCs isolation by the application of a new parameter serving as a marker of graft efficacy: chemotactic reactivity in SDF-1 gradient. In this part of our research we tested the most commonly used anticoagulants (ACD, CPDA-1, EDTA, heparin) and culture media (DME, IMDM, RPMI) in order to find the safest protocol for the cell isolation from $\mathrm{CB}, \mathrm{PB}$ and $\mathrm{BM}$.

\section{Material and methods}

Cells. MNCs were obtained from human CB, PB and BM. CB was obtained after consent during delivery from 5 healthy women at the Clinic of Obstetrics Pomeranian Medical University in Szczecin, Poland. PB was obtained from 5 healthy volunteers after informed consent was given. BM was obtained from 5 heparinized cadaveric organ donors (HCOD).

Isolation of MNCs from CB, PB and BM. Normal light-density MNCs were obtained after centrifugation over Gradisol L (Polfa Kutno) and, if necessary, depleted of adherent cells and T lymphocytes as described [11]. The cells were counted using a haemocytometer.

For multiparameter cell sorting purposes whole $\mathrm{CB}, \mathrm{PB}$, and $\mathrm{BM}$ were lysed in BD lysing buffer (BD Biosciences, San Jose, CA, USA) for $15 \mathrm{~min}$ at room temperature and washed twice in phosphate-buffered saline (PBS).

Chemotaxis assay. Cells were resuspended in IMDM with $0.5 \%$ bovine serum albumin (BSA) and were equilibrated for $10 \mathrm{~min}$ at $37^{\circ} \mathrm{C}$. Prewarmed serum-free medium containing $1 \mu \mathrm{g}$ SDF- 1 was added to the lower chambers of a Costar Transwell 24-well plate (Costar Corning, Cambridge, MA, USA). Aliquots of the cells suspension $(1 \times 105$ cells $/ 100 \mu \mathrm{L})$ were loaded onto the upper chambers, which were incubated for 3 hours $\left(37^{\circ} \mathrm{C}, 95 \%\right.$ humidity, $5 \%$ $\mathrm{CO}_{2}$ ), and cells from the lower chambers were scored using FACS analysis (FACScan, BD Biosciences, CA, USA). The results were presented as a chemotactic index (the ratio of the number of cells migrating toward the medium alone) [12].

Staining and isolation of HSCs and PSCs. A novel two-step isolation procedure was employed - removal of erythrocytes by hypotonic lysis combined with multiparameter sorting, as described previously [13-14]. Briefly, whole human CB, PB, and $\mathrm{BM}$ were depleted of erythrocytes by hypotonic solution (Lysing Buffer, BD Biosciences, San Jose, CA, USA). A single cell suspension was stained for lineage markers (CD2 clone RPA-2.10, CD3 clone UCHT1, CD14 clone M5E2, CD66b clone G10F5, CD24 clone ML5, CD56 clone NCAM16.2, CD16 clone 3G8, CD19 clone HIB19, CD235a clone GA-R2) conjugated with fluorescein isothiocyanate (FITC), CD45 (clone HI30) conjugated with phycoerythrin (PE) and combination of CXCR4 (clone 12G5) or CD133 (CD133/1) conjugated with APC, for 30 min on ice. After washing, they were analyzed by fluorescence-activated cell sorting (FACS) (BD Biosciences, San Jose, CA, USA). At least $10^{5}$ events were acquired and analyzed using Cell Quest software.

CXCR4 $4^{+}$lin-CD45-, CXCR4 $4^{+}$lin $^{-} \mathrm{CD} 45^{+}, \mathrm{AC}^{-} 33^{+}$lin $^{-} \mathrm{CD} 45^{-}$, $\mathrm{AC} 133^{+}$lin-CD45 ${ }^{+}$were analyzed and sorted from a suspension of $\mathrm{CB}, \mathrm{PB}$ and $\mathrm{BM} \mathrm{MNC}$ by multiparameter, live sterile cell sorting (BD FACSAria Cell-Sorting System, BD Biosciences, San Jose, CA, USA) [14].

Anticoagulants. Four commonly used anticoagulants were evaluated for short-term storage of the harvested BM, PB and BM cells: 1. Heparin $(5000 \mathrm{U} / \mathrm{mL}$, Gibco, USA)

2. Acid-citrate-dextrose (ACD) (Anticoagulant Citrate Dextrose Solution, USP, Baxter Healthcare Corporation, USA)

3. Citric-acid-phosphate-dextrose-adenine (CPDA-1) (Anticoagulant Citrate Phosphate Dextrose Adenine Solution with glucose, USP, Baxter Healthcare Corporation, USA)

4. Ethylenediaminetetraacetic acid (EDTA) (1\%, Lubelskie Przedsiebiorstwo Przemyslowo-Handlowe "Odczynniki Chemiczne", Poland)

The solutions of examined anticoagulants were dissolved in cooled $\left(4^{\circ} \mathrm{C}\right)$ phosphate-buffered saline (PBS, $\left.\mathrm{pH}=7.5\right)$ supplemented with penicillin-streptomycin (Gibco BRL, USA). CB, PB and $\mathrm{BM}$ cells after aspiration were suspended in different anticoagulant solutions in sterile propylene tubes $(50 \mathrm{~mL}$, Fisher, USA) and used immediately for further research or incubated for 24 hours at $4^{\circ} \mathrm{C}$.

Collecting media. Three different media were evaluated for shortterm storage of the harvested CB, PB and BM cells: 1) Dulbecco's modified Eagle's medium (DME), 2) Iscove's modified Dulbecco's medium (IMDM), 3) RPMI-1640 (RPMI) (Sigma-Aldrich Chemie $\mathrm{GmbH}$, Germany).

The media supplemented with heparin, penicillin and streptomycin (Gibco BRL, USA) were prepared on the day of CB, PB and $\mathrm{BM}$ harvest and refrigerated at $4^{\circ} \mathrm{C}$ in sterile propylene tubes $(50$ $\mathrm{mL}$, Fisher, USA). CB, PB and BM after aspiration were suspended in the examined collecting media and incubated $\left(4^{\circ} \mathrm{C}\right)$ for 24 hours.

Clonogenic assays. The clonogeneic growth of isolated cells was evaluated by in vitro clonogenic assays as described [11]. CFUGM colonies were stimulated with GM-CSF (5 ng/mL) + IL-3 (20 $\mathrm{U} / \mathrm{mL})+\mathrm{SCF}(10 \mathrm{ng} / \mathrm{mL})$. Colonies were counted with an inverted microscope on day 11 . The data were shown as percentage of the control values.

Apoptosis assays. The level of apoptosis was assessed using Annexin V (BD Biosciences, San Jose, CA, USA) following the manufacturer's specifications. Binding of fluorescein-conjugated Annexin $\mathrm{V}$ and propidium iodide (PI) was analyzed using flow cytometry (FACScan, BD Biosciences, CA, USA) [15].

Ethical issues. The procedure was approved by the Local Ethical Committee and it is in accordance with the Helsinki Declaration of 1975. Moreover, in every case of obtaining blood the person gave special consent. 

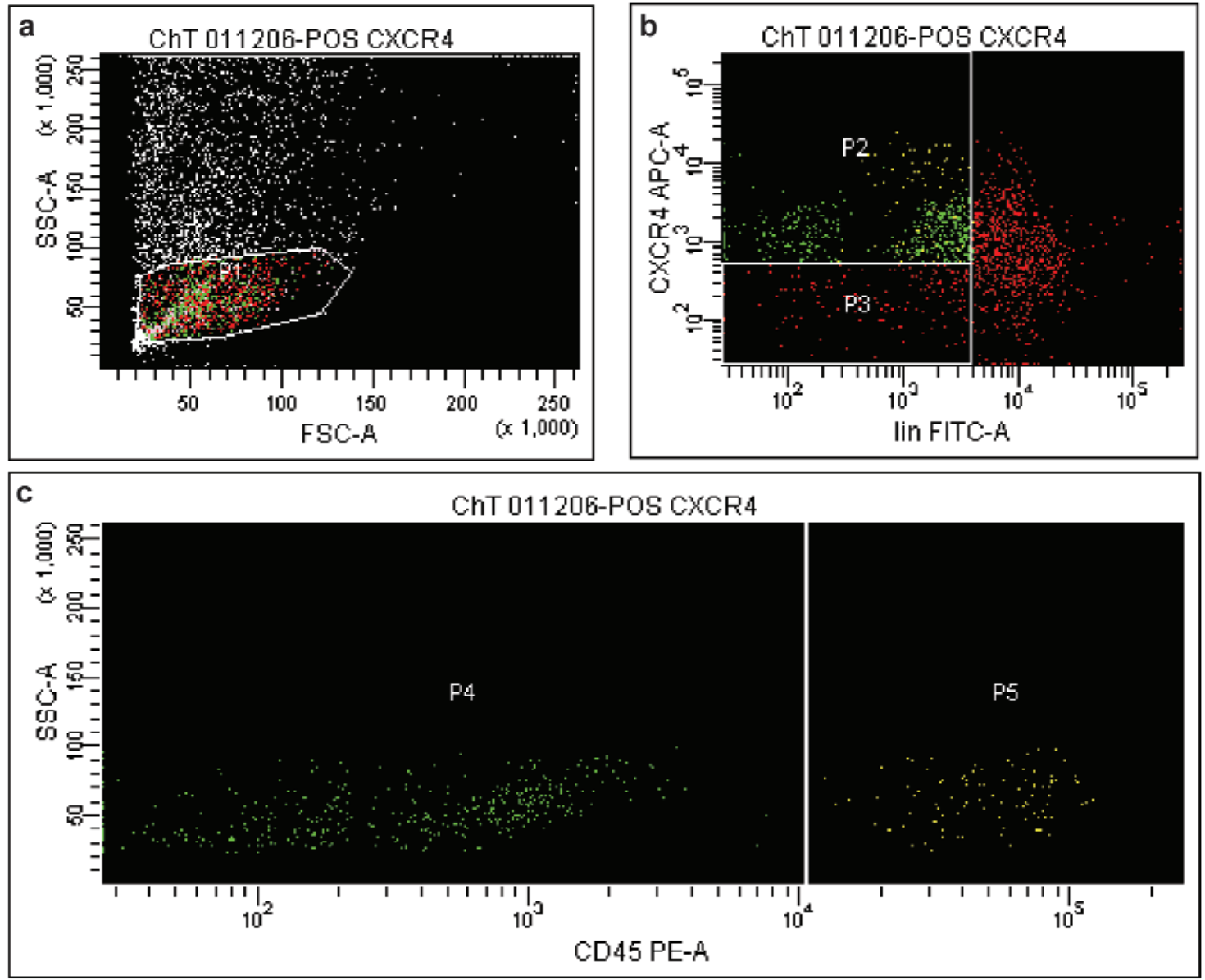

\begin{tabular}{lrrr|}
\hline Tube: POS CXCR4 & & & \\
Population & \#Events & \%Parent & \% Total \\
\hline All Events & 5,000 & & 100.0 \\
$\square$ P1 & 1,363 & 27.3 & 27.3 \\
$\square$ P4 & 485 & 35.6 & 9.7 \\
$\square$ P5 & 391 & 80.6 & 7.8 \\
$\square$ P3 & 94 & 19.4 & 1.9 \\
& 177 & 13.0 & 3.5 \\
\hline
\end{tabular}

Fig. 1. Representative FACS analysis of human umbilical CB MNCs collected from the lower chamber (cells that responded to SDF-1 gradient). Erythrocytes were removed by hypotonic lysis and CB MNCs were stained with lineage markers, CD45 and CXCR4. (a) Upper left - dot plot of human CB MNC; P1 gate - lymph gate. (b) Upper right - dot plot restricted to lymph gate; P2 gate - CXCR4 ${ }^{+}$Lin- cells; P3 gate - CXCR4- Lin- cells. (c) Lower - CXCR4 positive, lineage negative restricted (P2 gate) cells; P4 gate - indicates $\mathrm{CXCR}^{+}{ }^{+}$lin ${ }^{-}$ CD45- (PSC); P5 gate - indicates CXCR4 ${ }^{+} \operatorname{lin}^{-} \mathrm{CD} 45^{+}(\mathrm{HSC})$. Representative result is shown.

Statistical analysis. Arithmetic means and standard deviations were calculated on an IBM computer using Microsoft Excel (version 2003) software. Data were analyzed using the Student's t-test for unpaired samples. Statistical significance was defined as $\mathrm{p}<0.05$.

\section{Results}

First of all, we attempted to analyze the population of MNCs obtained from $\mathrm{CB}, \mathrm{PB}$, and $\mathrm{BM}$, which responded to SDF-1 gradient. In particular, we tried to isolate two different populations: $\mathrm{CXCR} 4^{+}{ }^{-1}{ }^{-} \mathrm{AC} 133^{+} \mathrm{CD} 45^{+}$ cells (referred as hematopoietic stem cells) and
$\mathrm{CXCR}^{+}{ }^{+}$lin ${ }^{-} \mathrm{AC} 133^{+} \mathrm{CD}^{-} 5^{-}$cells (referred as nonhematopoietic pluripotent stem cells) [14]. To obtain this aim, we employed a novel two-step isolation strategy involving the removal of erythrocytes by hypotonic lysis combined with multiparameter sorting. It was surprising that cells that responded to SDF-1 gradient (i.e. collected from the lower chamber of the transwell plate) were highly enriched in hematopoietic stem cells (HSCs) and even more in non-hematopoietic pluripotent stem cells (PSCs) (Fig. 1). In contrast, among the cells which did not respond to the chemokine (collected from the upper 

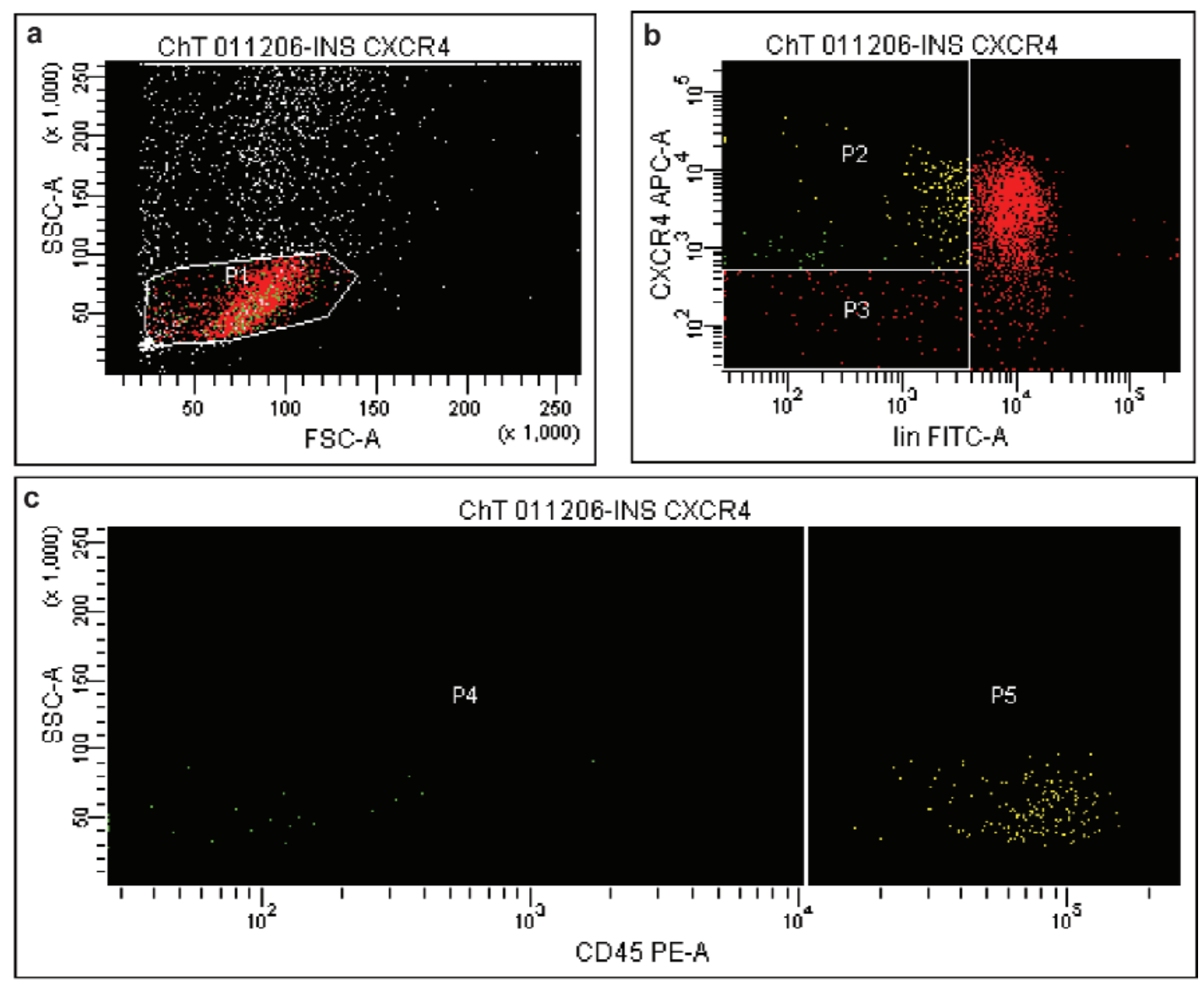

\begin{tabular}{|lrrr|}
\hline Tube: INS CXCR4 & & & \\
Population & \#Events & \%Parent & \%Total \\
$\square$ All Events & 5,000 & & 100.0 \\
$\square$ P1 & 2,309 & 46.2 & 46.2 \\
$\square$ P2 & 197 & 8.5 & 3.9 \\
$\square$ P4 & 25 & 12.7 & 0.5 \\
$\square$ P5 & 172 & 87.3 & 3.4 \\
$\square$ P3 & 88 & 3.8 & 1.8 \\
\hline
\end{tabular}

Fig. 2. Representative FACS analysis of human umbilical CB MNCs collected from the insert/upper chamber (cells that did not respond to SDF-1 gradient). Erythrocytes were removed by hypotonic lysis and CB MNCs were stained with lineage markers, CD45 and CXCR4. (a) Upper left - dot plot of human CB MNC; P1 gate - lymph gate. (b) Upper right - dot plot restricted to lymph gate; P2 gate - CXCR4 ${ }^{+}$ Lin- cells; P3 gate - CXCR4- Lin- cells. (c) Lower - CXCR4 positive, lineage negative restricted (P2 gate) cells; P4 gate - indicates $\mathrm{CXCR}^{+}{ }^{+}$lin $^{-} \mathrm{CD} 45^{-}$(PSC); P5 gate - indicates $\mathrm{CXCR} 4^{+} \operatorname{lin}^{-} \mathrm{CD} 45^{+}$(HSC). Representative result is shown.

Table 1. Characteristics of the population of $\mathrm{AC} 133^{+} \mathrm{lin}^{-} \mathrm{CD} 45^{-}(\mathrm{PSC})$ and $\mathrm{AC} 133^{+}$lin ${ }^{-} \mathrm{CD} 45^{+}$(HSC) from a suspension of $\mathrm{CB} \mathrm{MNC}(\mathrm{n}=5)$, which responded or not to SDF-1 gradient by multiparameter cell sorting. In each case 5000 events were acquired. The values refer to

\begin{tabular}{|c|c|c|}
\hline $\mathrm{n}=5$ & Cells that responded to SDI'- $(\% \pm \mathrm{SD})$ & Cells that did not respond to SDI'- $(\% \pm \mathrm{SD})$ \\
\hline HSC & $0.29 \pm 0.19$ & $0.12 \pm 0.16$ \\
\hline PSC & $3.66 \pm 3.26$ & $0.44 \pm 0.22$ \\
\hline
\end{tabular}

chamber of transwell plate) significant lower amount of the HSCs as well as PSCs was found (Fig. 2). The summary of chemotactic reactivity of different subpopulations of cells from CB is shown in Table 1 .
In order to evaluate the influence of different anticoagulants on the clonogenic potential, ability of chemotactic reactivity in SDF-1 gradient, and intensification of apoptosis of HSPCs, isolated from CB, PB 

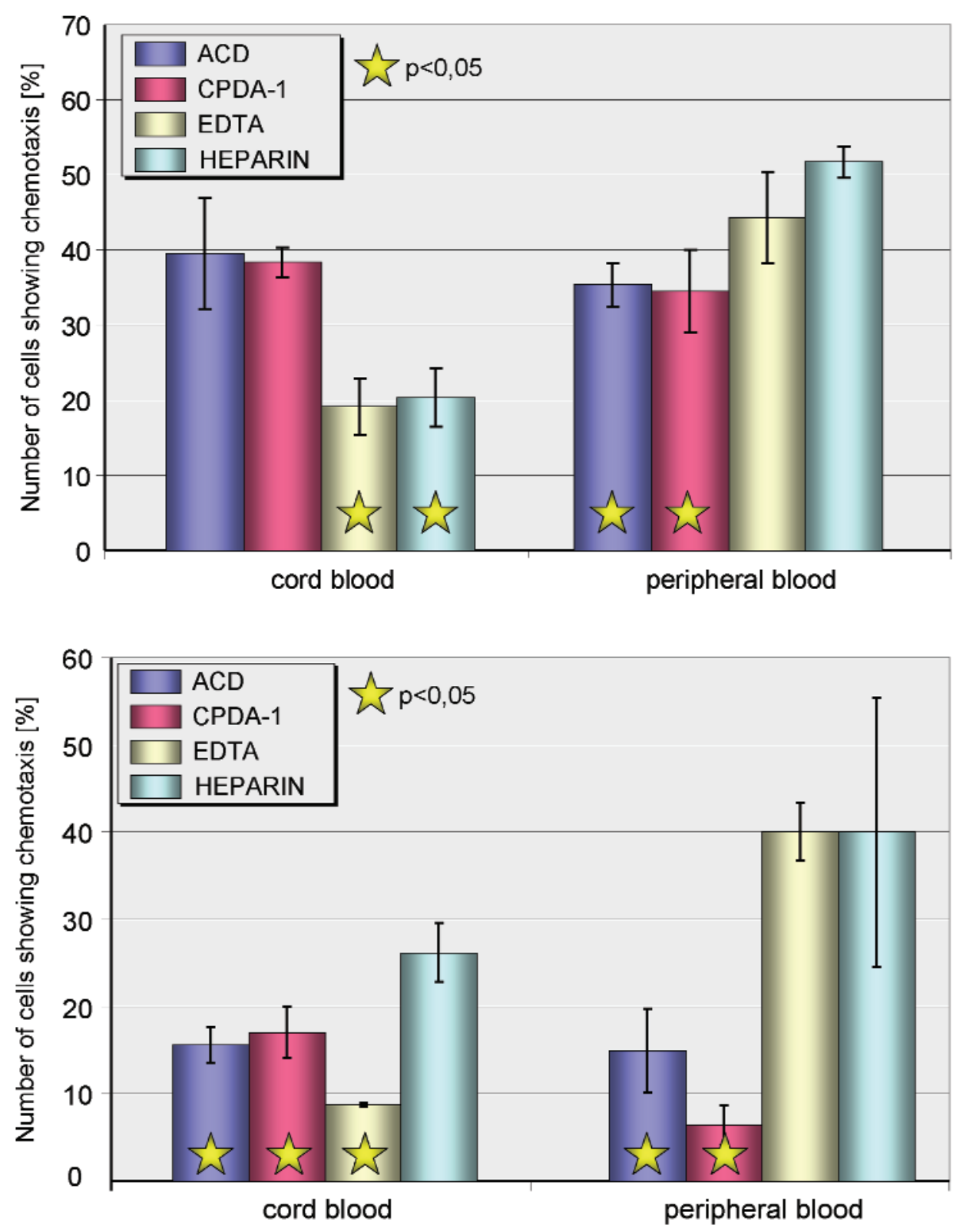

Fig. 3. The influence of different anticoagulants on chemotactic reactivity in SDF-1 gradient of $\mathrm{CB}$ and PB freshly isolated cells. The results are presented as a chemotactic index (the ratio of the number of cells migrating in SDF-1 gradient toward the medium alone).

Fig. 4. The influence of different anticoagulants on chemotactic reactivity in SDF-1 gradient of CB and $\mathrm{PB}$ cells stored at $4^{\circ} \mathrm{C}$ for 24 hours. The results are presented as a chemotactic index (the ratio of the number of cells migrating in SDF-1 gradient toward the medium alone).

and BM, we compared the effect of the most common anticoagulants such as heparin, ACD, CPDA-1 and EDTA. Our present results confirmed our previous studies $[11,16-20]$ on the clonogeneic potential and the level of apoptosis. In this study we focused mostly on the influence of different anticoagulants on chemotactic reactivity in SDF-1 gradient. We found that heparin was the most suitable and safe anticoagulant for freshly isolated PB and BM (not shown) HSPCs. ACD and CPDA-1 have a comparably good influence on HSPCs obtained from the CB (Fig. 3). Heparin also proved to be the most suitable anticoagulant for short-term storage (24h) of CB, PB, and BM (not shown) cells at $4^{\circ} \mathrm{C}$ in terms of chemotactic reactivity (Fig. 4). Hence, in our further studies of optimizing the short-term storage of $\mathrm{CB}, \mathrm{PB}$ and BM cells, we collected the cells into the medium supplemented with heparin as a standard anticoagulant.

Next, we evaluated the influence of different collecting media i.a. DME, IMDM, RPMI on chemotactic reactivity of $\mathrm{HSPCs}$ obtained from $\mathrm{CB}, \mathrm{PB}$ and $\mathrm{BM}$. The best collecting medium in all cases appeared to be IMDM (Fig. 5).

\section{Discussion}

Stem cell motility (migration, homing and release) is essential for the bone marrow repopulation and for the development of hematopoietic system [21]. Recently, it has become evident that the SDF-1-CXCR4 signaling axis plays a pivotal role in the homing and engraftment of HSPCs [1]. Moreover, the last scientific 


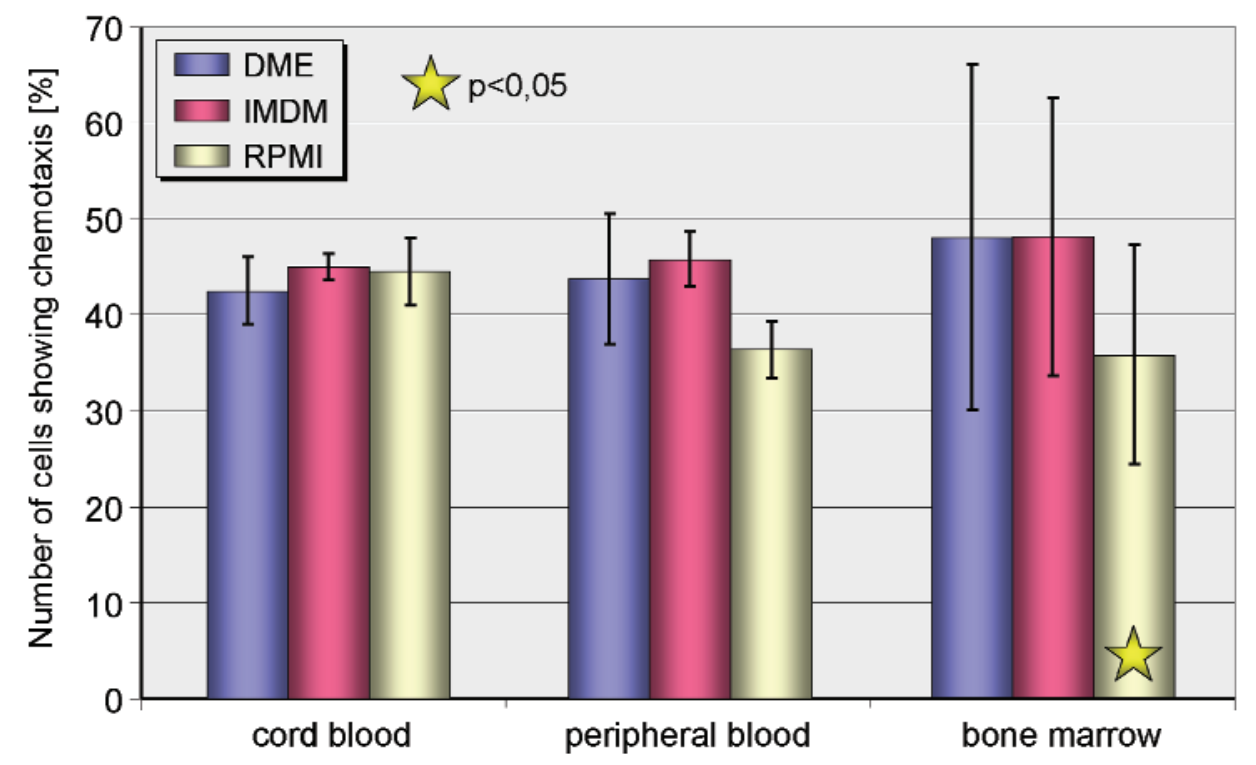

Fig. 5. The influence of different collecting medium on chemotactic reactivity in SDF-1 gradient of $\mathrm{CB}$, $\mathrm{PB}$ and $\mathrm{BM}$ cells stored at $4^{\circ} \mathrm{C}$ for 24 hours. The results are presented as a chemotactic index (the ratio of the number of cells migrating in SDF-1 gradient toward the medium alone). reports indicate that certain factors can positively influence the chemotactic response of HSPCs to SDF-1 (such as: fibrinogen, fibronectin, C3a anaphylatoxin, hyaluronic acid) [22-27], or negatively (e.g. polyene antibiotics) [27]. On the basis of these observations it may be concluded that the modulation of responsiveness of HSPCs to SDF-1 could be a key to better transplanttion. Therefore, two parameters are essential for HSPC homing to BM: reactivity of CXCR4 receptor on HSPCs in accordance with SDF-1 gradient and effective level of expression of SDF-1 in bone marrow microenvironment [8-9, 28-29].

Using multiparameter cell sorter, we examined the HSPCs attracted by SDF-1 on a single cell level. The population of cells, which participated in chemotactic process was highly enriched in $\mathrm{CXCR}^{+} \mathrm{lin}^{-}$ $\mathrm{AC} 133^{+} \mathrm{CD}^{4} 5^{+}$cells (HSCs) and, surprisingly, in CXCR4 ${ }^{+}$lin $^{-} \mathrm{AC} 133^{+} \mathrm{CD} 45^{-}$cells (PSCs) in quantitative amounts.

Application of optimalized HSPC isolating procedure with additional pro-chemotactic factors could have a great impact on successful transplantation. Because reactivity of HSPCs may depend on various factors, we selected here the best anticoagulant as well as collecting medium from among the most commonly used ones for short-term storage of HSPCs, by evaluating the ability of chemotactic reactivity in SDF-1 gradient, clonogenic potential, and intensification of apoptosis of $\mathrm{CB}, \mathrm{PB}$, and $\mathrm{BM}$ cells.

Although the reactivity of HSPCs in SDF-1 gradient is likely to be a critical factor responsible for hematopoietic graft efficacy, this crucial parameter is not routinely applied in transplant procedures in the clinic so far. Application of our results in standard hematologic protocols would enhance the HSPC grafting efficacy in clinical practice. We suggest that the functional chemotactic reactivity of HSPC across a gradient of SDF-1 concentration should become a key parameter determining hematopoietic graft efficacy.

Acknowledgements: The study was supported by grant No 2 P05A 06730 of the Polish Committee of Science to B.M.

\section{References}

[ 1] Kahn J, Byk T, Jansson-Sjostrand L, et al. Overexpression of CXCR4 on human CD34+ progenitors increases their proliferation, migration and NOD/SCID repopulation. Blood. 2004;103:2942-2949.

[ 2] Kijowski J, Baj-Krzyworzeka M, Majka M, et al. The SDF-1CXCR4 axis stimulates VEGF secretion and activates integrins but does not affect proliferation and survival in lymphohematopoietic cells. Stem Cells. 2001;19:453-466.

[ 3] Majka M, Janowska-Wieczorek A, Ratajczak J, et al. Stromal-derived factor 1 and thrombopoietin regulate distinct aspects of human megakaryopoiesis. Blood. 2000;96:41424151.

[4] Aiuti A, Webb IJ, Bleul C, Springer TA, Gutierrez-Ramos JC. The chemokine SDF-1 is a chemoattractant for human CD34 ${ }^{+}$ hematopoietic progenitor cells and provides a new mechanism to explain the mobilization of $\mathrm{CD}^{+} 4^{+}$progenitors to peripheral blood. J Exp Med. 1997;185:111-120.

[ 5] Kim CH, Broxmeyer HE. In vitro behavior of hematopoietic progenitor cells under the influence of chemoattractants: stromal cell-derived factor-1, steel factor, and the bone marrow environment. Blood. 1998;91:100-110.

[6] Lapidot T, Petit I. Current understanding of stem cell mobilization: the roles of chemokines, proteolytic enzymes, adhesion molecules, cytokines, and stromal cells. Exp Hematol. 2002;30:973-981.

[ 7] Nagasawa T, Hirota S, Tachibana K, et al. Defects of B-cell lymphopoiesis and bone marrow myelopoiesis in mice lacking the CXC chemokine PBSF/SDF-1. Nature. 1996;382: 635-638.

[ 8] $\mathrm{Ma} \mathrm{Q}$, Jones $\mathrm{D}$, Borghesani PR, et al. Impaired B-lymphopoiesis, myelopoiesis, and derailed cerebellar neuron migration in CXCR4- and SDF-1-deficient mice. Proc Natl Acad Sci U S A. 1998;95:9448-9453. 
[ 9] Zou Y-R, Kottmann AH, Kudora M, Taniuchi I, Littman DR. Function of the chemokine receptor CXCR-4 in haematopoiesis and in cerebellar development. Nature. 1998;393:595-599.

[10] Voermans C, Kooi ML, Rodenhuis S, van der Lelie H, van der Schoot CE, Gerritsen WR. In vitro migratory capacity of $\mathrm{CD} 4^{+}$cells is related to hematopoietic recovery after autologous stem cell transplantation. Blood. 2001;97:799-804.

[11] Machaliński B. Isolation of haematopoietic cells from heparinized cadaveric organs donors for transplantation purposes. Ann Acad Med Stetin. 1999;suppl: 118.

[12] Wysoczyński M, Reca R, Ratajczak J, et al. Incorporation of CXCR4 into membrane lipid rafts primes homing-related responses of hematopoietic stem/progenitor cells to an SDF1 gradient. Blood. 2005;195:40-48.

[13] Kucia M, Reca R, Campbell FR, et al. A population of very small embryonic-like (VSEL) CXCR $4^{+}$SSEA- $1^{+}$Oct- $4^{+}$stem cells identified in adult bone marrow. Leukemia. 2006;20: 857-869.

[14] Kucia M, Hałasa M, Wysoczyński M, et al. Morphological and molecular characterization of novel population of $\mathrm{CXCR}^{+}{ }^{+}$SSEA $-4^{+}$Oct- $4^{+}$very small embryonic-like cells purified from human cord blood - preliminary report. Leukemia. 2006;21:297-303.

[15] Koopman G, Reutelingsperger CP, Kuijten GA, et al. Annexin $\mathrm{V}$ for flow cytometric detection of phosphatidylserine expression of B cells undergoing apoptosis. Blood. 1994;84: 1415.

[16] Marlicz W, Paczkowski M, Kijowski J, et al. Isolation of hematopoietic stem cells from heparinized cadaveric multiple organ donors: potential clinical implications. Transplant Proc. 1999;31:2099.

[17] Machaliński B, Kijowski J, Marlicz W, et al. Heparinized cadaveric organ donors (HCOD) - a potential source of hematopoietic cells for transplantation and gene therapy. Transplantation. 2001;71:1003.

[18] Machaliński B, Paczkowski M, Kawa M, et al. An optimization of isolation of early hematopoietic cells from heparinized cadaveric organ donors. Transplant Proc. 2003;35:3096.

[19] Machaliński B, Ratajczak MZ. The effect of selected anticoagulants on the clonogenicity of human hematopoietic progenitors. Transplantation implications. Pol Arch Med Wewn. 1997;97:509-517.
[20] Machaliński B, Honczarenko MM, Gontarewicz A, et al. Isolation of human mononuclear cells from bone marrow, peripheral blood and cord blood using Ficoll-Paque (Pharmacia) and Gradisol L (Polfa). Comparative study. Pol Arch Med Wew. 1998;99:15-23.

[21] Lapidot T, Petit I, Kollet O. Current understanding of factors influencing stem cell mobilization. ASH Education Session on Stem Cell Mobilization. 2003.

[22] Janowska-Wieczorek A, Majka M, Kijowski J, et al. Plateletderived microparticles bind to hematopoietic stem/progenitor cells and enhance their engraftment. Blood. 2001;98:31433149.

[23] Reca R, Mastellos D, Majka M, et al. Functional receptor for $\mathrm{C} 3 \mathrm{a}$ anaphylatoxin is expressed by normal hematopoietic stem/progenitor cells, and C3a enhances their homing-related responses to SDF-1. Blood. 2003;101:3784-3793.

[24] Sudhoff T, Sohngen D. Circulating endothelial adhesion molecules (sE-selectin, sVCAM-1 and sICAM-1) during rHuGCSF-stimulated stem cell mobilization. $J$ Hematother Stem Cell Res. 2002;11:147-151.

[25] Avigdor A, Goichberg P, Shivtiel S, et al. CD44 and hyaluronic acid cooperate with SDF-1 in the trafficking of human $\mathrm{CD}^{+} 4^{+}$stem/progenitor cells to bone marrow. Blood. 2004;103:2981-2989.

[26] Kimura T, Boehmler AM, Seitz G, et al. The sphingosine 1-phosphate receptor agonist FTY720 supports CXCR4dependent migration and bone marrow homing of human CD34+ progenitor cells. Blood. 2004;103:4478-4486.

[27] Wysoczynski M, Reca R, Ratajczak J, et al. Incorporation of CXCR4 into membrane lipid rafts primes homing-related responses of hematopoietic stem/progenitor cells to an SDF-1 gradient. Blood. 2005;105:40-48.

[28] Tachibana K, Hirota S, Lizasa H, et al. The chemokine receptor CXCR4 is essential for vascularization of the gastrointestinal tract. Nature. 1998;393:591-594.

[29] Moore MA, Hattori K, Heissig B, et al. Mobilization of endothelial and hematopoietic stem and progenitor cells by adenovector-mediated elevation of serum levels of SDF-1, VEGF, and angiopoietin-1. Ann N Y Acad Sci. 2001;938:3645.

Submitted: 28 September, 2007 Accepted after reviews: 28 May, 2008 